Research Article

\title{
Study of Anatomical Types of Pterion for Pterional Surgical Approach
}

\author{
Sachin Patil', Dharmendra Kumar ${ }^{2}$
}

${ }^{1}$ Assistant Professor, Department of Anatomy, ANIIMS, Port Blair, Andaman and Nicobar Islands, India.

${ }^{2}$ Associate Professor \& Head, Department of Physical Medicine and Rehabilitation, ANIIMS, Port Blair, Andaman and Nicobar Islands, India.

DOI: https://doi.org/10.24321/2454.8642.201916

\section{I $\quad \mathbf{N} \quad \mathbf{F} \quad \mathbf{O}$}

\section{Corresponding Author:}

Dharmendra Kumar, Department of Anatomy, ANIIMS, Port Blair, Andaman and Nicobar Islands, India.

E-mail Id:

dharmendra744101@gmail.com

Orcid Id:

https://orcid.org/0000-0001-9722-5107

How to cite this article:

Patil S, Kumar D. Study of Anatomical Types of Pterion for Pterional Surgical Approach. Rec Adv Path Lab Med 2019; 5(3): 14-16.

Date of Submission: 2019-07-15

Date of Acceptance: 2019-09-18

\section{$\begin{array}{llllllll}\mathbf{A} & \mathbf{B} & \mathbf{S} & \mathbf{T} & \mathbf{R} & \mathbf{A} & \mathbf{C} & \mathbf{T}\end{array}$}

Introduction: Pterion is useful anatomical landmark for neurosurgeons during operations on frontal lobe tumours, extradural haemorrhage, Roca's speech area or pathologies of middle cerebral artery.

Material and Methods: This study was conducted in the on 120 dry human skulls. On the both side of each skull, the morphology of pterion was examined based on Murphy's classification.

Results: On examining the sutural pattern and types of pterion we found that Sphenoparietal type of pterion was most common type while the least common type was the epipteric type of pterion. Percentage of types was Sphenoparietal type $73.75 \%$, Fronto temporal type $9.08 \%$, stellate type $20 \%$ and epipteric type $7.16 \%$.

Conclusion: Types of the pterion in normal skulls shows great degree of variations among individuals and different racial groups. Therefore, precise and scientific data ar e required when performing intracranial surgery.

Keywords: Asterion, Pterion, Skull, Suture

\section{Introduction}

Pterion is an $\mathrm{H}$ shaped suture located on lateral side above the zygomatic arch on either side of skull. It formed by union of four bones, the frontal and parietal bones superiorly and the greater wing of sphenoid and squamous temporal inferiorly. ${ }^{1}$ Embryologically it represents the site of anterolateral fontanelle of neonatal skull. It is membranous at birth but get fully ossified by third month after birth. ${ }^{2}$ Pterion is useful anatomical landmark for neurosurgeons during operations on frontal lobe tumours, extradural haemorrhage, Roca's speech area or pathologies of middle cerebral artery. ${ }^{3}$ Pterion is also significant landmark used in anthropometry. The pterion is one of the weakest parts of the skull commonly injured during sports like boxing, cricket, rugby and other high intensity sports. Pterion has been classified by different authors into 4-6 morphological types. Best known classification is by Murphy's given in 1956 into four types-sphenoparietal, frontotemporal, stellate, and epipteric. ${ }^{4}$

The present study was conducted to document the various types of pterion on basis of Murphy's in Indian population.

\section{Materials and Methods}

This study was conducted in the on 120 dry human skulls of unknown sex and age from the bone bank of our medical college. Any skull with gross pathology or abnormality or damage were excluded from study. On the both side of each skull, the morphology of pterion was examined 
based on Murphy's classification into four types: 1 . Sphenoparietal type; 2 . Fronto temporal type; 3 . Stellate type and 4. Epipteric type. The presence of sutural or epipteric bones was also noted. The types of pterion were sorted and documented into tables. The data was compared with the findings of previous studies and analysed.

\section{Result}

On examining the sutural pattern and types of pterion we found that Sphenoparietal type of pterion was most common type while the least common type was the epipteric type of pterion (Table 1 and Figure 1). Our study shows following types of pterion.

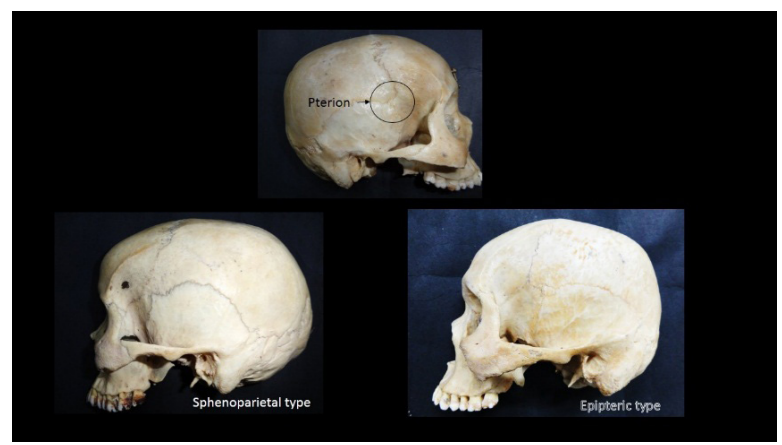

Figure I.Most common and least common type of pterion in our study

- Spheno-parietal type (73.75\%): Greater wing of sphenoid articulates with the parietal bone to form the letter ' $\mathrm{H}$ '.

- Frontotemporal type (9.08\%): Squamous part of the temporal bone articulates with the frontal bone.

- Stellate type (20\%): Here all bones articulate at a point in the form of letter ' $K$ '.

- Epipteric type (7.16\%): A sutural bone is lodged between the 4 bones forming the pterion.

Table 1 shows the different types of pterion in our study.

\section{Discussion}

In present study we observed all four types of pterionsphenoparietal, stellate, stellate and epipteric. Table 2 shows comparisons of observation of present study with previous studies. Sphenoparietal was the most common type of pterion in present study, $73.75 \%$ among total pterion, which was comparable to the previous studies. ${ }^{5-7}$

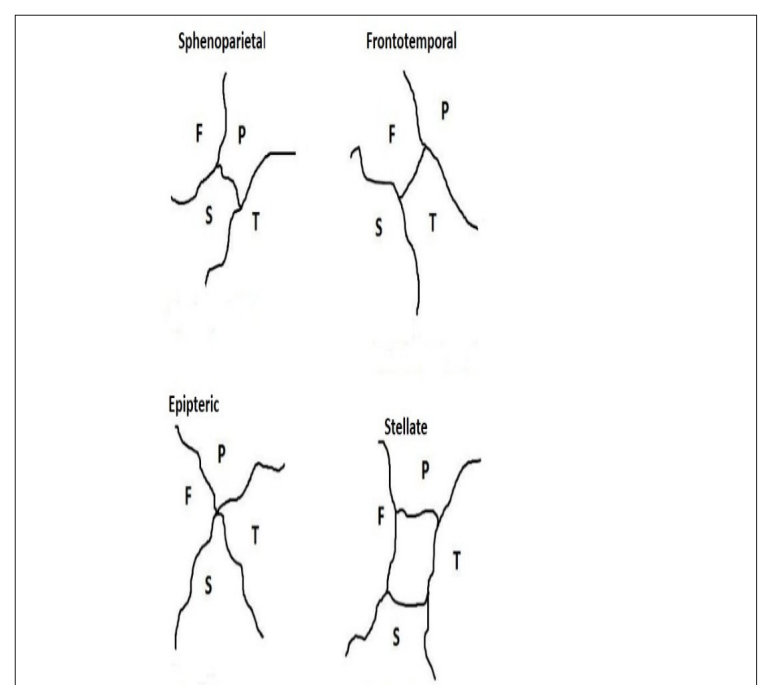

Figure 2.Different types of pterion in our study

Table I.The percentage of four types of pterion in current study

\begin{tabular}{|c|c|c|c|}
\hline Type of pterion & Right (120) & Left (120) & Total (240) \\
\hline $\begin{array}{c}\text { Spheno-parietal } \\
\text { type }\end{array}$ & $90(75 \%)$ & $\begin{array}{c}87 \\
(72.5 \%)\end{array}$ & $\begin{array}{c}177 \\
(73.75 \%)\end{array}$ \\
\hline $\begin{array}{c}\text { Frontotemporal } \\
\text { type }\end{array}$ & $11(9 \%)$ & $\begin{array}{c}11 \\
(9.17 \%)\end{array}$ & $22(9.08 \%)$ \\
\hline Stellate type & $12(10 \%)$ & $12(10 \%)$ & $24(20 \%)$ \\
\hline Epipteric type & $7(6 \%)$ & $\begin{array}{c}10 \\
(8.33 \%)\end{array}$ & $17(7.16 \%)$ \\
\hline
\end{tabular}

The ethnic and region wise variations in the type of pterion are due to various factors contributing to skull growth. ${ }^{7}$ These factors include genetic factors and environmental factors. ${ }^{8,9}$ According to Chao et al. successful removal of sylvian fissure lipoma by pterion keyhole surgery requires the detail knowledge of morphology and morphometry of pterion. ${ }^{10,11,12}$ The wormian bones can cause weakness in skull and extend the fractures. The presence of wormian bones provides false diagnosis of fractures radiologically or during surgery may lead to complications during burr hole. ${ }^{13,14}$ The extensive knowledge of pterion types and nearby landmarks is crucial for neurosurgeons in the management and treatment of vascular microsurgery and neurosurgery via pterion approach. ${ }^{15,16}$

Table 2.Comparison of the percentage of four types of pterion in different studies

\begin{tabular}{|c|c|c|c|c|c|}
\hline Study & Sample size & Sphenoparietal & Frontotemporal & Stellate & Epipteric \\
\hline Mats-umura G et al. $^{17}$ & 614 & $79.10 \%$ & $2.60 \%$ & $17.7 \%$ & $0.60 \%$ \\
\hline Saxena RC et al. $^{3}$ & 203 & $84.72 \%$ & $10.01 \%$ & $5.17 \%$ & $0.0 \%$ \\
\hline Sudha R et al. $^{8}$ & 150 & $80 \%$ & $3 \%$ & $5.30 \%$ & $11.30 \%$ \\
\hline Mod-asiya UP et al. $^{12}$ & 220 & $80.9 \%$ & $0.0 \%$ & $10.9 \%$ & $8.18 \%$ \\
\hline Present study & 120 & $73.75 \%$ & $9.08 \%$ & $20 \%$ & $7.16 \%$ \\
\hline
\end{tabular}




\section{Conclusion}

Types of the pterion in normal skulls shows great degree of variations among individuals and different racial groups. Sex and side also affect the type of the pterion. Therefore, precise and scientific data are required when performing intracranial surgery. Preoperative radiological imaging like X-rays, CT and MRI of the pterion should be done to determine a safe location for performing surgical and interventional procedures.

\section{Acknowledgement: None}

\section{Conflict of Interest: None}

\section{References}

1. Lee UY, Park DK, Kwon SO et al. Morphological analysis of the pterion in Korean. Korean J Phys Anthropol 2001; 14(4): 281-289.

2. Ersoy M, Evliyaoglu C, Bozkurt MC et al. Epipteric bones in the pterion may be a surgical pitfall. Minim Invasive Neurosurg 2003; 46(6): 363-365.

3. Saxena RC, Bilodi AKS, Mane SS et al. Study of pterion in skulls of Awadh area-in and around Lucknow. Kathmandu Univ Med J 2003; 1(1): 32-33.

4. Mwachaka PM, Hassanali J, Odula P. Sutural morphology of the pterion and asterion among adult Kenyans. Braz J Morphol Sci 2009; 26(1): 4-7.

5. Hussain Saheb S, Mavishetter GF, Thomas ST et al. Anatomical position of pterion among the Indian for lateral skull approach. Biomedicine 2010; 30(3): 391393.

6. Apinhasmit W, Chompoopong S, Chaisuksunt V et al. Anatomical consideration of pterion and its related references in Thai dry skulls for Pterional surgical approach. Journal of the Medical Association of Thailand 2011; 94(2): 205-214.

7. Praba MA, Venkatramaniah. Morphometric Study of different types of Pterion and It's relation with middle meningeal artery in dry skulls of Tamil Nadu. Journal of Pharmaceutical and Biomedical Sciences 2012; 21(21): 1-4.

8. Sudha R, Sridevi C, Ezhilarasi M. Anatomical variations in the formation of pterion and asterion in South Indian population. Int J Cur Res Rev 2013; 5(9): 92-101.

9. Hariprasad, Bezbaruah NK, Mishra A et al. Morphometric analysis of pterion: A clinic-Anatomical study in North Indian dry skulls. Innovative Journal of Medical and Health Science 2015; 5(5): 201-205.

10. Gumusburun E, Sevim A, Katkici U et al. A study of sutural bones in Anatolian- Ottoman skulls. International Journal of Anthropology 1997;12(2): 43-48.

11. Chao SC, Shen CC, Cheng WY. Microsurgical removal of sylvian fissure lipoma with pterion keyhole approachcase report and review of the literature. Surg Neurol
2008; 70 (Suppl 1): S1-90.

12. Day JD, Tschabitscher M. Anatomic position of the asterion. Neurosurgery 1998; 42(1): 198-199.

13. Modasiya UP, Kanani SD. Study of pterion and asterion in adult human skulls of north Gujarat region. Ind $\mathrm{C}$ Clin Anat Physiol. 2018; 5(3): 353-356.

14. Natekar PE, de Souza FM, Natekar SP. Pterion: An anatomical variation and surgical landmark. Indian Journal of Otology 2011; 17(2): 83-85.

15. Glorieux FH. Osteogenesis Imperfecta. Best Pract Res Clin Rheumatol 2008; 22: 85-100.

16. Oon $\mathrm{CL}, \mathrm{Yu} \mathrm{SF}$. Posterior parietal fractures in infancy and early childhood. Singapore Med J 1971; 12: 13-16.

17. Matsumura G, Kida K, Ichikawa R et al. Pterion and epipteric bones in Japanese adults and fetuses, with special reference to their formation and variations. Kaibogaku Zasshi 1991; 66(5): 462-471. 